\title{
Neuropsicología y género
}

La organización funcional del cerebro y las capacidades mentales de hombres y mujeres presentan diferencias significativas. Las investigaciones en ciencias cognitivas, particularmente neuropsicología, así lo constatan. Las diferencias comprenden un amplio espectro, desde actos reflejos a comportamientos más complejos. La acción de las hormonas sexuales conforma redes neurales y procesos bioquímicos diferentes en los cerebros de hombres y mujeres, ya desde los primeros meses de vida intrauterina. Pero también las experiencias y aprendizajes en los contextos socioculturales conforma y organiza el cerebro de cada persona originando capacidades y comportamientos propios y diferenciales.

Palabras Clave: Neuropsicología y Género. Diferencias cerebrales-mentales entre hombres y mujeres. Cerebro sexual, cognición y emoción.

\section{Introducción}

La década de 1990, calificada como década del cerebro, ha supuesto un avance espectacular en el conocimiento. Las neurociencias, particularmente la neuropsicología, se han situado en la vanguardia de la investigación. Las tecnologías de
The brain-mind functional organization of men and women shows significative differences. The cognitive sciences investigations, neuropsychology in particular, verify it, particulary in neuropsychology. The differences constitute an ample spectrum, from reflex actions to more complex behaviors. The action of sexual hormons forms neural nets and different biochemical processes in the brains of men and women, from the beginning months of intrauterine life. But experiences in sociocultural contexts also shape and organize the brain of each person causing one's own and differential capabilities and behavior.

Key Words: Neuropsychology and gender. Brain-mind differences between men and women. The sexual brain, cognition and emotion.

neuroimagen han posibilitado observaciones y experimentos revolucionarios sobre los procesos perceptivos, motrices, cognitivos, lingüísticos y emocionales del ser humano. Se han realizado estudios sobre las diferencias cerebrales-mentales 
entre hombres y mujeres. Polémicas anteriores como herencia-medio, naturalezacultura se abordan en la actualidad con datos nuevos. Numerosas investigaciones neuropsicológicas evidencian diferencias significativas entre hombres y mujeres en la organización funcional del cerebro y la actividad mental. Investigaciones relevantes replantean hoy cuestiones tradicionales sobre los condicionantes biológicos y culturales en el conocer, querer, sentir y actuar de hombres y mujeres.

La neuropsicología es una disciplina muy consolidada y acotada, que goza de gran reconocimiento y prestigio y que está ofreciendo conocimientos sorprendentes en los últimos años $(1,2,3)$. Sobre género se dispone hoy de gran cantidad de publicaciones muy dispersas y de diferentes procedencias, por lo que resulta más problemático enmarcarlas en programas de investigación coherentes. Sobre cuestiones de género tratan muchas disciplinas y existe gran diversidad conceptual y metodológica $(4,5,6)$.

No cabe en la actualidad adoptar posturas simplistas y dicotómicas de oposición de sexo frente a género, entendiendo que sexo hace referencia a los aspectos biológicos de dimorfismo sexual, es decir macho frente a hembra; mientras que género agrupa los aspectos psicológicos, sociales y culturales, es decir, lo que en una determinada sociedad se considera describe y prescribe como propio y diferencial de ser hombre o mujer. Tal oposición entre biología y cultura tan vigente en la tradición no sólo es simplista, sino falsa.

Tradicionalmente lo referente a sexo se ha abordado desde la genética, endocri- nología, anatomía, fisiología y neurología; mientras que el género ha sido objeto de las ciencias sociales, psicología, sociología y antropología, principalmente. Pero catalogar sexo como biológico y género como psicosocial imposibilita la adecuada comprensión de la realidad, al permanecer enredado en las redes categoriales tradicionales de oposición herencia-medio, naturaleza-crianza, biología-cultura $(7,8)$.

De entrada, en la realidad no se dan esas categorías discretas y separadas, un dimorfismo sexual varón-mujer, sino un polimorfismo sexual. Así, además de la correspondencia más armónica entre los distintos niveles, genético, endocrinológico, fisiológico, neurológico, presente en hombres y mujeres, se dan también discordancias entre los niveles señalados en casos más minoritarios de indefinición, bisexualidad y cambio de sexo.

En segundo lugar, este polimorfismo sexual se conforma a lo largo de la vida de la persona y se vivencia de maneras diversas en identidades únicas e irrepetibles. Cada persona estructura su yo, hace suya su propia corporeidad sexualizada y es más o menos consciente de su forma de percibir, pensar, sentir y actuar como ser humano.

En tercer lugar, la persona vive su sexualidad en contextos socioculturales determinados, asumiendo y exteriorizando unos determinados roles, estereotipos y prejuicios.

Lo biológico y lo social están siempre presentes en la configuración de la identidad y comportamiento personales, y para dar cuenta de lo humano se requiere un marco explicativo bio-psico-social. Las 
distintas disciplinas científicas han dado prioridad a unos factores u otros según pertenezcan al ámbito de las ciencias naturales o sociales. Las investigaciones neuropsicológicas ofrecen en la actualidad una perspectiva privilegiada para explicar la interacción de factores biológicos y sociales.

Sexo genotípico, sexo fenotípico, identificación de sexo

Los aproximadamente 35.000 genes que recogen la memoria filogenética de la especie humana se agrupan en 23 pares de cromosomas. El par 23, cuando es XX, determina el sexo de mujer, y cuando es XY de varón. El cromosoma Y es el más pequeño, con 60 genes, mientras los otros cromosomas tienen miles. Un gen del cromosoma Y, el gen Sry, activa en la sexta semana de vida intrauterina el desarrollo de los testículos, que a su vez producirán hormonas andrógenas, la testosterona, que se distribuye por todo el embrión estableciendo las pautas de estructuración corporal propias del varón. La testosterona es responsable de la masculinización del cuerpo humano en los diversos sistemas, músculo-esquelético, cardiovascular, y nervioso, particularmente el cerebro.

Cuando el par de cromosomas es XX, la segunda $X$ envía instrucciones para fabricar ovarios, que producirán los estrógenos, que a su vez conformarán la estructuración corporal propia de la mujer. La feminización del cuerpo de mujer afecta todos los sistemas, desde el sexual reproductor, hasta el nervioso central. De modo que si no está presente el cromosoma Y, no se forman los órganos genitales masculinos y lo que se desarrollan son los genitales propios de la mujer. Podemos afirmar que genéticamente Adán nace de la costilla de Eva.

A las seis semanas del desarrollo embrionario humano se forman las gónadas primordiales. Fijados a las gónadas están dos conjuntos de tubos, los conductos de Müller y Wolff, a partir de los cuales se generarán los genitales internos. Al mismo tiempo se desarrolla una estructura indiferenciada o surco urogenital que da origen a los genitales externos.

Cuando en los embriones XY se activa el gen Sry, produce una proteína denominada factor determinante testicular o TDF, que instruye el desarrollo de los testículos, los cuales secretan la testosterona y la hormona inhibidora de los conductos de Müller (HIM), impidiendo así que tales conductos se desarrollen, y posibilitando el desarrollo de los conductos de Wolff y las vesículas seminales. El tejido que rodea el surco urogenital se convierte en el pene y el escroto. En ausencia de TDF (en los embriones XX), la gónada se diferencia en ovario, los conductos de Wolf degeneran y los conductos de Müller desarrollan los oviductos, el útero y el cuello uterino. El tejido que rodea el surco urogenital se convierte en el clítoris, los labios y la vagina. Así pues, el desarrollo del fenotipo femenino depende de la ausencia de TDF y de la ausencia consiguiente de andrógenos, mientras que la presencia de TDF y la producción de andrógenos al comienzo de la vida intrauterina llevan a la diferenciación de cuerpo y cerebro masculino $(9,10,11,12)$.

Este patrón general en el desarrollo de la mayoría de los seres humanos presenta 
excepciones como en el caso de personas con sexo indiferenciado o cambio de sexo. Ello puede deberse a factores varios, como no activación del gen Sry, aunque esté presente el cromosoma Y, en el par $23 \mathrm{XY}$, lo que llevará a una conformación corporal externa propia de mujer, pero sin útero. En otros casos, embriones XX quedan afectados por suministro de hormonas andrógenas que ha tomado la madre, para prevenir un aborto por ejemplo. Tratamiento con testosterona, en edades posteriores, puede masculinizar el cuerpo de una mujer, con cambios manifiestos en su estructura corporal, sistema muscular, cardiovascular y lo que más nos interesa aquí, el sistema cerebral, desarrollando así modalidades mentales masculinas, con perfiles cognitivos y emocionales más propios de hombre.

La palabra sexo presenta significados diferentes según se trate de: sexo genotípico, sexo fenotípico e identificación de sexo. El sexo genotípico está determinado por dos cromosomas sexuales, $\mathrm{X}$ e Y. Cromosomas XX es una mujer genotípica, $\mathrm{XY}$ es un hombre genotípico. El sexo fenotípico está determinado por el desarrollo de los genitales internos y externos. Si el plan de desarrollo no se altera, el genotipo XX conduce a una persona con ovarios, oviductos, útero, cuello uterino, clítoris, labios genitales y vagina: una hembra fenotípica. Igualmente el genotipo XY lleva a una persona con testículos, vesículas seminales, pene y escroto: un macho fenotípico. La identificación de sexo está determinada por la percepción y valoración subjetiva que una persona tiene de su sexo, en un contexto sociocultural determinado. La identidad de sexo implica autovaloración, proyectos y expectativas determinadas y ajuste a tales expectativas, de acuerdo con los rasgos diferenciales asociados con un sexo $\mathrm{u}$ otro.

Sexo genotípico, sexo fenotípico e identificación de sexo no siempre y necesariamente van alineados, dando lugar a diversos problemas biológicos, psicológicos y sociales. Por ejemplo, algunas personas pueden sufrir, debido a una identificación que no coincide con su sexo, y considerarse como miembros del sexo opuesto. La discrepancia puede ser tan fuerte que recurren a la cirugía y tratamiento hormonal para conseguir que su sexo fenotípico se ajuste con su identificación de sexo. Otras personas son genotípicamente XY, pero fenotípicamente mujeres, debido a un gen defectuoso para receptor de andrógenos, lo que se llama feminización testicular. Esta deficiencia de los receptores conduce al desarrollo de los genitales internos de un hombre y los genitales externos de una mujer. Por ello se consideran como mujeres aunque tienen un cromosoma Y. En general no son conscientes de su condición hasta la pubertad, al no tener menstruación. En este caso la identidad de sexo se corresponde con el fenotipo sexual externo, pero no con el genotipo.

Otra mezcla sexual son los hombres genotípicos y mujeres fenotípicas al comienzo de la vida, pero cuyo fenotipo cambia en la pubertad. Hasta la niñez son mujeres fenotípicas, al carecer de un enzima que promueve el desarrollo temprano de los genitales masculinos. Sus genitales son ambiguos, pero de aspecto más bien femenino, y habitualmente son criados como 
mujeres y la socialización es femenina. Pero en la pubertad, cuando la secreción testicular de andrógenos es más elevada, el clítoris evoluciona a un pene y los testículos descienden convirtiéndose en hombres fenotípicos.

Mujeres genotípicas con hiperplasia suprarrenal congénita tienen glándulas suprarrenales muy activas durante el desarrollo, con la consiguiente producción anormalmente alta de andrógenos. Estas mujeres muestran conductas masculinas y, de adultas, tienden a establecer relaciones homosexuales. Los niveles elevados de andrógenos estimulan circuitos encefálicos sexualmente dimórficos, conformando pautas de comportamiento masculinas.

La investigación disponible explica la serie continua de la sexualidad humana, desde diferencias en la estructura funcional cerebral. Estos dimorfismos encefálicos dependen de la influencia en la fase temprana de hormonas que actúan sobre los núcleos encefálicos que median diferentes aspectos de la conducta sexual. Los niveles bajos de andrógenos en el cerebro de un hombre al comienzo de la vida pueden conducir a un encéfalo relativamente femenino en los hombres genotípicos, mientras que los niveles elevados de andrógenos en los cerebros de mujeres genotípicas llevan a un cerebro más masculinizado $(12,13,14)$.

\section{Diferencias cerebro-mente de hombre y mujer}

Dentro de los universales cognitivos, lingüísticos y emocionales que comparten todos los miembros de la especie humana, mujeres y hombres tienden a presentar di- ferencias en la organización funcional del cerebro, y por tanto en sus capacidades mentales. Unos autores han resaltado precisamente estas diferencias, mientras que para otros las estructuras y procesos generales y comunes son lo prioritario y las características diferenciales quedan en un segundo término.

Frente a los planteamientos tradicionales que consideran la mente como una capacidad o competencia de carácter general, la investigación disponible en diversas ciencias cognitivas corrobora la teoría modular de la mente $(15,19)$. Los supuestos que denominaremos «posición heredada» son compartidos por posiciones empiristas, asociacionistas y conductistas, que consideran la mente «tanquam tabula rasa» al nacer el individuo, y que se irá llenando, o escribiendo según esta metáfora, a lo largo de la vida con las experiencias y contenidos específicos. También el modelo de ordenador propio de la psicología cognitiva computacional concibe la mente como un procesador de propósito general. La epistemología genética de Piaget y la psicología sociocultural de Vygotski, se sitúan asimismo en este marco.

La concepción modular caracteriza la mente como un conjunto de subsistemas o módulos especializados en procesar información, memorias diversas, inteligencias múltiples, etc. Cada módulo es específico $y$ especializado en un tipo de proceso o actividad. Así serían diferentes los módulos o sistemas responsables del lenguaje, la fabricación de herramientas, la orientación en el espacio, la interacción con otras personas en las relaciones sociales, el 
autocontrol personal. Tales módulos no están localizados en compartimentos, sino muy distribuidos en el cerebro, pero las redes neurales que los componen están altamente especializadas $(15,16,17,18)$.

Particularmente la neuropsicología experimental y clínica confirma la arquitectura modular de la mente. Los estudios de las afasias, amnesias, agnosias, apraxias, etc. evidencian la organización funcional del cerebro de tipo modular. Los estudios con PET y IRMF muestran cada vez con más detalle las áreas y módulos cerebrales responsables de procesos mentales $(1,2,3,15,16,17,18)$.

También desde otras ciencias como la psicología evolucionista y la primatología se confirma la teoría modular. La mente humana es resultado de un largo proceso filogenético, en el que han ido apareciendo sucesivas estructuras cerebrales para enfrentarse a problemas distintos, adaptarse, sobrevivir y dejar descendencia (20).

El modelo estándar de las ciencias sociales ha impuesto como académicamente correcto, y también políticamente, la consideración de que las diferencias entre los seres humanos, y más concretamente entre hombres y mujeres, son debidas predominantemente al medio sociocultural, los aprendizajes y socialización. Pero estos supuestos ambientalistas en extremo son muy difíciles de mantener ante las investigaciones disponibles $(21,22)$.

Conviene dejar sentado que las diferencias en capacidades mentales ligadas al sexo son también de carácter modular, y no se trata de defender superioridad mental general o global de un sexo frente a otro, como a veces se ha querido probar me- diante el cociente intelectual o medidas similares.

Como tendencia general, las mujeres superan a los hombres en las pruebas de velocidad perceptiva, cuando hay que identificar rápidamente objetos concordantes. También en pruebas de fluidez en la ideación, por ejemplo enumerar objetos que sean del mismo color; y en pruebas de fluidez verbal, en las que se han de encontrar palabras que empiecen con la misma letra. Se comportan con más éxito en tareas manuales de precisión, que requieren una coordinación motriz fina. Realizan mejor que los hombres las pruebas de cálculo matemático.

Los hombres superan a las mujeres en determinadas tareas espaciales, como en las tareas que implican hacer girar mentalmente un objeto. Muestran mayor precisión que las mujeres en habilidades motoras dirigidas a un blanco, como lanzar o interceptar proyectiles. Realizan mejor las pruebas de identificación de figuras en marcos complejos, por ejemplo encontrar una determinada figura u objeto escondida en una figura más compleja. También superan a las mujeres en pruebas de razonamiento matemático $(23,24,25,26)$.

Pero conviene hacer algunas precisiones respecto a las diferencias señaladas entre hombres y mujeres. Se trata de medidas estadísticas, que establecen medias de puntuación, de las que cualquier individuo puede distanciarse más o menos. Dado que en muchas pruebas que dan valores medios de las diferencias de origen sexual existe una superposición muy grande de los resultados de hombres y mujeres, es preciso tener en cuenta las varia- 
ciones dentro de cada sexo para poder estimar con más fiabilidad las diferencias entre los sexos. Por ejemplo, si en una prueba la puntuación media es de 105 para las mujeres y 100 para los hombres, los resultados de las mujeres se distribuyen de 100 a 110, y los de los hombres de 95 a 105 , la diferencia sería más significativa que si los resultados variaran en las mujeres entre 50 y 150 , y en los hombres entre 45 y 145. En tal caso la superposición de puntuaciones sería mucho mayor.

La desviación típica proporciona una medida de la variación de las puntuaciones registradas en el interior de un grupo. Para comparar la cuantía de la diferencia debida al sexo en tareas distintas, se divide la diferencia entre grupos de sexo por dicha desviación típica, obteniendo un cociente denominado «efecto de tamaño» que suele considerarse pequeño cuando es inferior a 0,5. Distintos estudios parecen mostrar que las diferencias entre sexos son menos significativas en pruebas de vocabulario, razonamiento, fluidez verbal e ideativa, donde las mujeres tienden a superar a los hombres. Y son más acusadas y significativas en pruebas tales como rotación espacial, precisión en puntería, a favor de los hombres.

Las diferencias en las capacidades mentales por razón de sexo no sólo aparecen después de la adolescencia. Ya están presentes desde edades tempranas como han mostrado diferentes estudios transversales y longitudinales desde los primeros años de vida ( 24, 27, 28 ).

Además de los estudios de carácter más psicométrico que se han venido realizando tradicionalmente en el marco de la psicología diferencial y evolutiva sobre diferencias en capacidades mentales ligadas a sexo, se han realizado estudios sobre la influencia de las hormonas sexuales en la conformación del cerebro. Las hormonas sexuales no sólo transforman los genitales, también condicionan los comportamientos, al modificar la estructura neural del cerebro $(12,13,14)$.

Los efectos de la exposición a las hormonas sexuales son distintos según el momento de la vida en que se producen. Cuando la edad es más temprana, periodo uterino, los efectos son más duraderos, al modificar la organización cerebral de forma más permanente. Son más organizativos y estructurales al aplicarse en periodos más sensibles. Las mismas hormonas aplicadas en etapas posteriores de la vida causarán efectos menores.

Los estudios con roedores han sido especialmente reveladores. Adiferencia de los seres humanos, en las ratas la diferenciación sexual cerebral no se produce en el periodo fetal, sino inmediatamente después del nacimiento. Por ello los experimentos son más fáciles de realizar. Cuando a un ratón con genitales masculinos se le priva al nacer de andrógenos, mediante castración o bloqueo de la función hormonal, se debilita su comportamiento sexual masculino como la copulación con hembras, y en cambio se refuerzan comportamientos femeninos como arqueado del dorso. Paralelamente, si a una hembra, al nacer, se le administra andrógenos mostrará en la edad adulta más comportamientos de tipo masculino, su cerebro será de tipo masculino. La rata tiene cuerpo de hembra y cerebro de macho. 
El comportamiento reproductor depende del hipotálamo. Estudios han demostrado que un área basal del hipotálamo aparece mayor en los ratones machos que en las hembras. Tal incremento está en función de los andrógenos en etapas prenatal y postnatal. También en el cerebro humano se han encontrado tales diferencias (12, 13, 14).

Los efectos de la temprana exposición a las hormonas sexuales no se limitan al comportamiento sexual o reproductor, también se expresan en otros comportamientos diferenciales entre machos y hembras, como orientación espacial y reconocimiento de pautas, juegos, etc. Estos comportamientos diferenciales se han observado en distintas especies de mamíferos y también en el ser humano.

Niñas que fueron expuestas en etapa prenatal a dosis altas de andrógenos evidenciaron en su desarrollo tales diferencias en la línea que venimos señalando respecto a orientación espacial, resolución de problemas espaciales, reconocimiento de patrones, velocidad perceptiva, razonamiento matemático, fluidez verbal.

Algunos estudios incluso han registrado diferencias en tales tareas mentales en función de los cambios hormonales en el ciclo menstrual de la mujer, y también dependiendo de los ciclos estacionales del año, tanto en hombres como mujeres. Cabe afirmar que con tratamiento de testosterona se masculiniza no solo el cuerpo, sino también la mente, es decir las propiedades de la organización funcional del cerebro (24, $25,26,28)$.

Otra vía para estudiar las diferencias entre cerebro masculino y femenino es a partir de las funciones mentales alteradas como consecuencia de lesiones cerebrales acotadas. En primer lugar respecto a la misma asimetría y lateralización cerebral. Sabemos que el cerebro humano está asimétricamente organizado de modo que el hemisferio izquierdo procesa la información y controla la motricidad de la parte derecha del cuerpo, mientras que el hemisferio derecho controla la parte izquierda del cuerpo. El hemisferio izquierdo es responsable del lenguaje en el $98 \%$ de la población que es diestra, mientras que en el hemisferio derecho tienden a radicar funciones de carácter visoespacial y razonamiento matemático. El cuerpo calloso está formado por el conjunto de fibras neurales que comunican entre sí los dos hemisferios.

Diferentes estudios han constatado menor asimetría en mujeres que en hombres, lo que explicaría el hecho de que las lesiones cerebrales en mujeres suelen tener menos secuelas, por la capacidad de otras áreas neurales para hacerse cargo de funciones lesionadas. Algunos estudios han mostrado diferencias en la conformación del cuerpo calloso en hombres y mujeres. Éstas tendrían mayor cantidad de fibras y conexiones. Otros estudios no han evidenciado tal dato, pero sí formas diferenciales de organización funcional $(1,2$, 24, 26).

Se han estudiado las capacidades visoespaciales, de orientación y ejecución, razonamiento matemático de hombres con lesión en el cerebro derecho; así como las capacidades lingüísticas en mujeres con lesión en el hemisferio izquierdo. Los estudios de afasias, agnosias, apraxias etc, 
en líneas generales parecen indicar una organización funcional del cerebro diferente en hombres y mujeres, ya desde edades muy tempranas.

Otra fuente de investigación en la actualidad es el estudio de personas con cerebro sano. Los avances en las tecnologías de neuroimagen está posibilitando este tipo de estudios. Se han realizado estudios longitudinales con más de quince mil niños y niñas a lo largo de dieciseis años, registrando los comportamientos manifiestos y rendimiento en tareas como juego, razonamiento verbal y matemático, orientación espacial y resolución de problemas, motricidad y velocidad en la ejecución, etc., registrando también la actividad cerebral diferencial de unos y otros.

Se han realizado tratamientos de cambio de sexo a base de testosterona, analizando comportamientos tales como: orientación espacial, rapidez motora, memoria visual y lingüística, reconocimiento de rostros, respuestas emocionales, registrando a la vez los cambios en el funcionamiento de áreas cerebrales a lo largo del proceso de masculinización. Tales cambios en áreas y pautas de activación neural se evidencian con sólo seis meses de tratamiento en personas jóvenes.

Un estudio con sesenta y una personas adultas, treinta y siete hombres y veinticuatro mujeres, y una media de veintisiete años de edad, han mostrado diferencias significativas entre ambos sexos en diecisiete zonas del cerebro, de veintiseis áreas estudiadas. Los datos están en sintonía con lo señalado hasta aquí. Cabe resaltar las diferencias registradas en las regiones del sistema límbico. Los hombres muestran mayor actividad en las regiones basales, temporales, del sistema límbico, mientras que en las mujeres la activación es mayor en el área tálamo-cingular .

En el comportamiento emocional, los hombres tienen mayor tendencia a expresar su estado emocional mediante conductas agresivas, mientras que las mujeres prefieren la mediación simbólica, la verbalización y la expresión oral $(24,28)$.

Aportaciones desde otras disciplinas como la paleontología y la psicología evolucionista proporcionan claves para dar cuenta de las diferencias en capacidades mentales de hombres y mujeres. Parece razonable aceptar que tales diferencias son resultado de un proceso evolutivo que recogió, por selección natural, aquellas ventajas adaptativas para la supervivencia de la especie. El cerebro humano es el resultado de millones de años de evolución, hasta las últimas conquistas de nuestra especie, el lenguaje, hace unos ciento cincuenta mil años.

A lo largo de miles de años de nuestra historia filogenética, el hombre vivía en grupos limitados de cazadores-recolectores con división del trabajo entre los sexos. Los varones se encargarían de la caza mayor, que exigía recorrer largas distancias, orientarse en los desplazamientos, representar mapas mentales del territorio, desarrollar rapidez en el lanzamiento de proyectiles, etc. También eran responsables de la defensa del grupo contra depredadores y enemigos. Las mujeres recolectarían alimentos, atenderían el hogar, preparando comida, vestimenta, y especialmente volcadas a la atención, protección y cuidado de los hijos. 
Tales especializaciones habrían dispuesto diferentes presiones de selección a varones y mujeres. Aquellos necesitarían encontrar caminos a través de largas distancias y habilidades motrices para acertar en un blanco. Las mujeres precisarían orientación en espacios próximos, amplitud de memoria para los detalles, capacidades motrices finas, y una especial discriminación para los pequeños cambios en el entorno, muy especialmente en el aspecto y comportamiento de los hijos, sus necesidades y demandas, sus estados emocionales $(29,30)$.

\section{Conclusiones}

Las diferencias en las conductas de machos y hembras comprenden un amplio espectro, desde actos reflejos hasta comportamientos más complejos. Las diferencias en los diferentes niveles de complejidad conductual están en función de diferencias en la organización del cerebro. Ciertamente los conocimientos disponibles sobre la base neural de estas diferencias es más consistente en los experimentos con animales. Pero las evidencias sobre las diferencias en los cerebros humanos relacionadas con el sexo son también manifiestas.

Los dimorfismos encefálicos en función del sexo, especialmente en el área hipotalámica y cuerpo calloso, están sólidamente establecidos en animales de laboratorio, particularmente en roedores y primates. El desarrollo de tales dimorfismos sexuales en el sistema nervioso central es resultado del sexo genotípico y la acción de las gónadas con las hormonas producidas.
Las áreas del hipotálamo aparecen especialmente implicadas en los dimorfismos sexuales. En ratas y monos, los núcleos de esta región cerebral desempeñan una función clave en los mecanismos de pulsión sexual, copulación, orientación sexual, relaciones parentales. Si bien no se pueden extrapolar mecánicamente estos resultados de investigación animal al comportamiento humano, y los dimorfismos sexuales del cerebro humano son más complejos, con los datos disponibles, parece razonable admitir que la acción de las hormonas sexuales en el cuerpo, y particularmente en el cerebro, conforma redes neuronales y procesos bioquímicos diferentes en hombres y mujeres, ya desde los primeros meses de vida intrauterina, posibilitando así aspectos diferenciales en el continuum del comportamiento humano, desde el comportamiento sexual hasta los procesos cognitivos, lingüísticos y emocionales. Parece establecido que hay diferencias relevantes ligadas al sexo en los cerebrosmentes de hombres y mujeres. Y tales diferencias se van conformando desde edades tempranas de vida intrauterina $(11,12$, 13, 14, 33 ).

Pero también es incuestionable que las experiencias y aprendizajes en entornos socioculturales reestructura y organiza el cerebro, recablea las redes neurales, como han dejado establecido estudios de cerebros de personas con profesiones tan distintas, como taxistas, pianistas, violinistas, etc. Y también la reestructuración que como consecuencia de aprendizajes y rehabilitación ocurre en el cerebro de personas con lesiones, ceguera, sordera, afasia, amnesia, etc. ( $1,2,31,32,33)$. 
Nuestro cerebro no evolucionó para poder leer, escribir, manejar un ordenador, pilotar una nave espacial, y tantas cosas más, pero puede realizar todo eso y mucho más gracias a las estructuras conseguidas mediante selección natural para adaptarse a otros tipos de demandas en medios naturales y sociales muy distintos a los de nuestro tiempo. Parece también plausible aceptar que en el futuro las exigencias con las que se ha de enfrentar el cerebro humano de hombres y mujeres, condicionarán el cableado de sus cerebros, posibilitando capacidades y aptitudes, modos de pensar, sentir y comportarse. Sociedades y culturas más simétricas y equilibradas, con roles y profesiones compartidas por personas de uno y otro sexo también dejarán su impacto en la conformación física de los cerebros y por tanto en los tipos y modalidades de mentes de hombres y mujeres.

\section{BIBLIOGRAFÍA}

1. Kolb, B. y Whishaw, Q., An introduction to brain and behavior, N. York, Woth Publishers, 2001.

2. Gazzaniga, M., The New Cognitive Neuroscience, Cambridge, MIT Press, 2000.

3. Damasio, A., La sensación de lo que ocurre, Madrid, Debate, 2001.

4. Fernández, J., Género y sociedad, Madrid, Pirámide, 1998.

5. Reinisch, J.M.; Rosenblunt, L.A. y Sanders, S.A., Masculinity and feminity. Oxford, University Press, 1987.

6. Tannen, D., Género y discurso. Barcelona, Paidos, 1994.

7. Becker, J.B., Behavioral endocrinology. Cambridge, MIT, 1992.

8. Feinberg, T. y Farah, M., Behavioral Neurology and Neuropsychology. N. York, Mc Graw-Hill, 1997.

9. Johnson, M. y Everitt, J., Essential Reproduction, Oxford, Blackwell Scientific, 1998.

10. Koopman, P. J. et al., «Male development of chromosomally female mice transgrenic for Sry». Nature, 1991, 351, 117-121.

11. Fausto-Sterling, A., Myths of Gender: Biological Theories About Women and Men, N. York, Basic Books, 1992.

12. LeVay, S., The Sexual Brain, Cambridge MA, MIT Press, 1993.

13. LeVay, S., «A Difference in hypothalamic structure between heterosexual and homosexual men», Science, 1991, 253, 1034-1037.

14. Zhou, J. et al., «A sex difference in the human brain and its relation to transsexuality», Nature, 1995, 378, 68-70.

15. García García, E., Mente y cerebro, Madrid, Síntesis, 2001.

16. Fuster, J., Memory in the Cerebral Cortex, Massachussets, MIT, 1995.

17. Fuster, J., Redes de memoria, Investigación y Ciencia, julio, 1997.

18. LeDoux, J., El cerebro emocional, Barcelona, Planeta, 1999. 
19. Gardner, H., Intelligence Reframed, N. York, Basic Books, 1999.

20. Barkow,J; Cosmides,L; Tooby,J., The Adapted Mind. New YorK, Oxford Univ. Press, 1992

21. Pinker, S., El instinto del lenguaje, Madrid, Alianza, 1996.

22. Pinker, S., The Blank Slate, New York, Viking, 2002.

23. Kimura, D., Are men's and women's brains really different? Canadian psychology, 1987, 28, 183-187

24. Kimura, D., Cerebro de varón, cerebro de mujer. Investigación y ciencia, 1992, 77-84

25. Kimura, D., Sex, sexual orientation and sex hormones influence human cognitive function. Current Opinion in Neurobiology, 1996, 6, 259-263

26. Kimura, D., Sex and Cognition, Cambridge, MA, MIT Press, 1999.

27. Archer, J., Sex differences in social behavior: Are the social role andevolutionary explanations compatible?, American Psichologist, 1996, 51, 909-917

28. Gur, R. et al., Sex differences in brain gray and white matter in healthy young adults, Journal of Neuroscience, 1999, 19, 4065-407

29. Mithen, S., Arqueología de la mente, Barcelona, Crítica, 1998.

30. Arsuaga, J.L. y Martinez, I., La especie elegida, Madrid, Temas de hoy, 1998.

31. Elbert, Th., y Rockstroh, B., Una huella en el cortex de los violinistas. Mundo Científico, 1996, 172, 880-883

32. Neville, H. y Bavelier, D., Aumento de las áreas visuales en los sordos. Mundo Científico, 1996, 172, 854-857

33. Purves, D. et al., Neurociencia. Madrid, Panamericana, 2001.

* Profesor Titular de Psicología Básica

Dpto. Psicología Básica II. Procesos Cognitivos.

Universidad Complutense. Madrid

Facultad de Filosofía, B-22

Ciudad Universitaria, 28040-Madrid

Fax: 913946020

E-M: garmi@correo.cop.es 